\title{
Effects of Sodium Lauryl Sulfate on Co- electrodeposition of Nickel and Fly Ash Particles
}

\author{
Nguyen Viet Hue \\ Department of Materials Protection, The Institute of Materials Science (IMS) \\ 18 Hoang Quoc Viet, Cau Giay, 10 000, Hanoi, Vietnam \\ Nguyen Ngoc Phong \\ Department of Materials Protection, The Institute of Materials Science (IMS) \\ 18 Hoang Quoc Viet, Cau Giay, 10 000, Hanoi, Vietnam \\ Pham Hong Hanh \\ Department of Materials Protection, The Institute of Materials Science (IMS) \\ 18 Hoang Quoc Viet, Cau Giay, 10 000, Hanoi, Vietnam
}

\begin{abstract}
The nickel/fly ash composite plating was realized in the presence of sodium lauryl sulfate (SLS) as a stimulator in Watts bath. Morphology of coating was studied by SEM; microhardness by Hardness tester and cathodic behaviors of additives and corrosion resistance by electrochemical polarization. The results showed that sodium lauryl sulfate facilitated the deposition of fly ash onto the nickel matrix. At fly ash $50 \mathrm{~g} / \mathrm{L}$, the amount of fly ash in the deposit was $16.5 \%$ at lauryl sulfate $10 \mathrm{~g} / \mathrm{L}$, compared with $8.2 \%$ at lauryl sulfate $0.1 \mathrm{~g} / \mathrm{L}$. The micro-hardness and corrosion resistance of coating increased with increasing fly ash powder in the deposit as well as lauryl sulfate concentration in the bath. The microhardness of the coating was HV 210 at fly ash $5 \mathrm{~g} / \mathrm{L}$ without lauryl sulfate; in the presence of $100 \mathrm{~g} / \mathrm{L} \mathrm{of} \mathrm{fly} \mathrm{ash} \mathrm{and}$ $10 \mathrm{~g} / \mathrm{L}$ of lauryl sulfate, this value increased to HV 490 ( $c f$. HV 198 for pure nickel coating).
\end{abstract}

Keywords - Composite plating, fly ash, micro-hardness, corrosion resistance, stimulator

\section{INTRODUCTION}

Composite plating has been used to improve surface characteristics of materials such as mechanical and electrochemical properties[1,2]. Composite coating properties are dependent on characteristics and amount of inert particles in the deposit [3-5]. The amount of particles in the deposit can be increased by their concentration in the electrolyte, also by controlling the plating conditions (e.g. current density, stirring speed, particles concentration). Some researchers have attempted to increase particle amount in deposit by using additives so called stimulators (promoters). Organic compounds used as a stimulator were described in the work of Shrestha [6]. In their study, an amount of $\mathrm{SiC}$ in $\mathrm{Ni} / \mathrm{SiC}$ composite plating reached $45 \%$ (volume fraction) using AZTAB (Azobenzene moiety) at a concentration of $0.6 \mathrm{~g} / \mathrm{L}$. Inorganic compounds as a Co-cation or rare earth element salts were also studied as a stimulator in composite plating [5,7-10].

The surfactants as stimulators can vary compositions, microstructure of matrix as well increase the inert particles amount in deposit [11], because surfactants are able to improve the stability of a suspension by increasing the wettability and surface charge of suspended particles, and also enhance the electrostatic adsorption of suspended particles on the cathode surface by increasing their positive charge [12-15].

Sodium lauryl sulfate (SLS) with the formula $\mathrm{CH}_{3}\left(\mathrm{CH}_{2}\right)_{11} \mathrm{OSO}_{3} \mathrm{Na}$ is an organ-sulfate consisting of a 12-carbon tail attached to the sulfate group giving the material the amphiphilic properties. As SLS is derived from inexpensive coconut and palm oils, it is a common component of many domestic cleaning products. Also, SLS is an anionic surfactant used as a wetting reagent or a brightener for Ni plating. On the other hand, SLS was studied as a stimulator for Ni composite plating [10,15-21]. 
Fly ash (FA) - a byproduct of thermal electric power plants has been used for manufacturing of alloys composites [22], polymer composites [23-24], zinc electroplating composite coatings [25].

\section{EXPERIMENTAL}

\section{A. Plating bath}

Electrodeposition was realized in Watts bath, its compositions $(\mathrm{g} / \mathrm{L})$ were: $\mathrm{Ni}_{2} \mathrm{SO}_{4} \cdot 6 \mathrm{H}_{2} \mathrm{O}: 250 ; \mathrm{NiCl}_{2} \cdot 6 \mathrm{H}_{2} \mathrm{O}: 40$; $\mathrm{H}_{3} \mathrm{BO}_{3}$ : 40; inert particles FA $(6-8 \mu \mathrm{m})$ : 5-100; surfactant SLS: 0.1-10.

\section{B. Materials and study methods}

Plating materials, chemicals, samples preparation before and after plating; also the determination of coating thickness by Axiover 40 MAT (Carl Zeiss); the hardness by IndentaMet 1106 (Buehler); corrosion resistance of coating by electrochemical polarization with PARSTAT 2273 and FA amount in deposit by SEM Jeol 6490-2300 in combination with EDX and/or gravimetric method were described in our previous paper [26,27].

\section{Plating conditions}

From our research ${ }^{27}$, the maximum amount of FA included in the composite deposit was achieved at a current density of $2 \mathrm{~A} / \mathrm{dm}^{2}$, in a plating solution of $\mathrm{pH} 4$, at a temperature of $50^{\circ} \mathrm{C}$ and a stirring speed of $250 \mathrm{rpm}$. These conditions were repeated again in present work.

\section{EXPERIMENT AND RESULT}

\section{A. Cathodic polarization study}

The cathodic behavior of different constituents of plating bath was studied by cathodic polarization (Fig. 1) at a scan rate of $0.1 \mathrm{mV} / \mathrm{s}$. It can be seen that the cathodic polarization curves of pure nickel (curve 1) and nickel composite plating with different FA angd SLS concentrations in the solution (curve 2-5) were nearly coincided. As the cathodic potentials moved towards negative, the deposition rate of Ni-cation increased to $-0.4 \mathrm{~V}$. Then the deposition of $\mathrm{Ni}$ reached a stable state at a current density of $10^{-4} \mathrm{~A} / \mathrm{cm}^{2}$ in a potential range from -0.4 to $-0.7 \mathrm{~V}$; below potential of - $0.7 \mathrm{~V}$, hydrogen gas appeared.

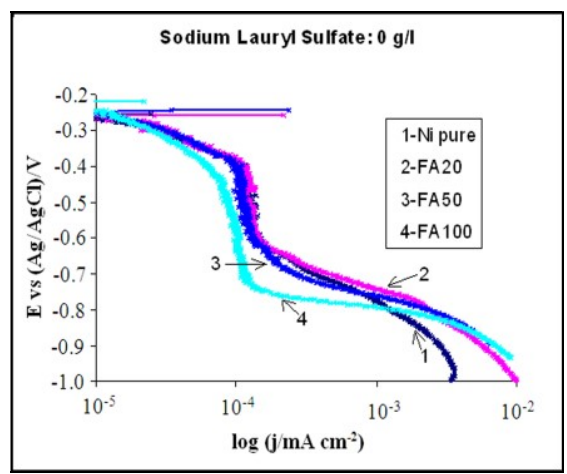

(a)

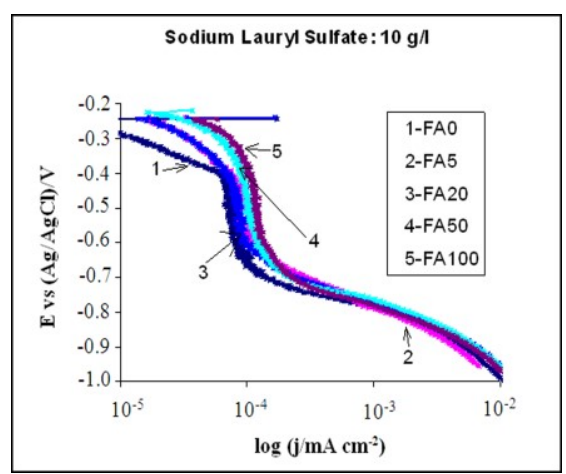

(b)

Figure 1. Cathodic polarization curves of nickel deposition at scan rate: $0.1 \mathrm{mV} / \mathrm{s}$ with different additives concentrations in the plating bath $(\mathrm{g} / \mathrm{L})$ : (a) SLS: 0; FA: 20, 50, 100; (b) SLS: 10; FA: 5, 20, 50, 100

The similarity of cathodic polarization curves revealed that FA as well as SLS had no effect on the deposition of $\mathrm{Ni}$ cation, however, at the FA concentration of $100 \mathrm{~g} \mathrm{~L}^{-1}$, the deposition of $\mathrm{Ni}$ cation exhibited a slowdown at a low range of the deposit current density (curve 4, Fig. 1a). This may be due to blocking effect of the FA particles at the cathode surface. 
As a wetting reagent for Ni plating, SLS was capable to adsorb on the cathode surface, this adsorbed layer decreased the deposit rate of $\mathrm{Ni}$ cations and reinforcing particles. This affected the crystallization kinetics of $\mathrm{Ni}$ and $\mathrm{Ni} / \mathrm{FA}$ composite plating resulting in the different coating microstructures (Fig. 2b,c).

\section{B. Surface morphology study}

The morphology of Ni and Ni-composite plating was studied by SEM/EDX and shown in Fig. 2. It has been observed that the microstructure of Ni coating became finer even in the presence of only FA as showed in Fig $2 \mathrm{~b}$. In the simultaneous presence of FA $(50 \mathrm{~g} / \mathrm{L})$ and SLS $(10 \mathrm{~g} / \mathrm{L})$, the microstructure of coating was changed (Fig. 2c). In this case, the size of coating crystalline was in the range of 2-3 $\mu \mathrm{m}$ similar to the one in the case without SLS (Fig. $2 b)$. However, it was observed that in the presence of SLS the microstructure of coating seemed being denser. In some areas the crystals aggregated forming granular forms (Fig. 2c).

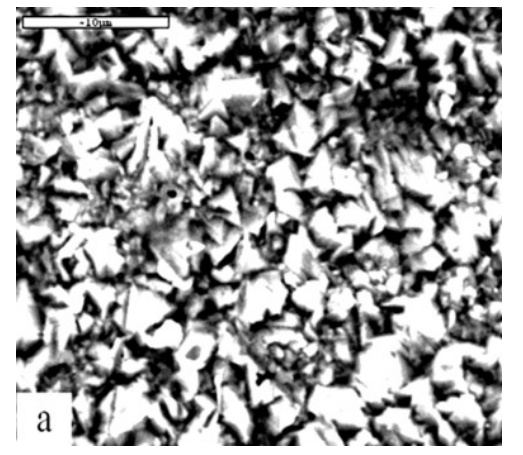

(a)

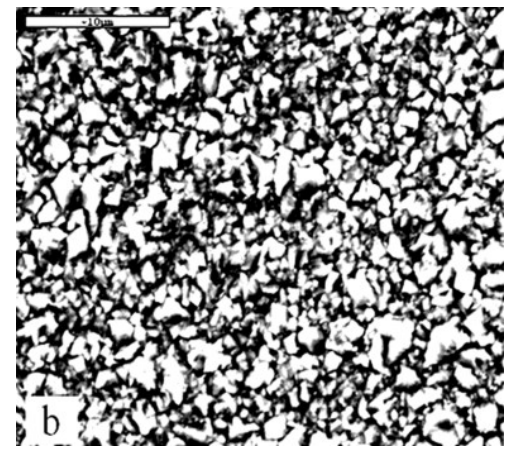

(b)

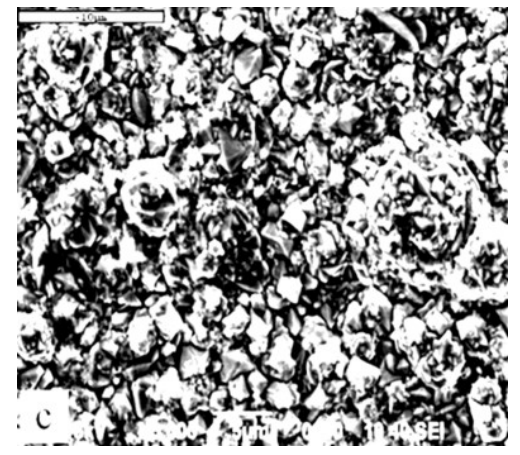

(c)

Figure 2. SEM microphotographs of $\mathrm{Ni}$ and $\mathrm{Ni} / \mathrm{Fa}$ composite at different additives concentrations $(\mathrm{g} / \mathrm{L})$

(a) $\mathrm{Ni}$; (b) Ni/FA50; (c) Ni/FA50-SLS10; (bar = $10 \mu \mathrm{m})$

\section{Amount of FA in the deposit}

The separate and total amount of $\mathrm{SiO}_{2}$ and $\mathrm{Al}_{2} \mathrm{O}_{3}$ was determined and the results were illustrated in Fig. 3. It can be seen that the FA amount in the deposit increased with increasing FA and SLS concentrations in plating bath. FA amount of $18.8 \%$ (mass fraction) in the deposit was obtained at FA $100 \mathrm{~g} / \mathrm{L}$ and SLS $10 \mathrm{~g} / \mathrm{L}$. Experiments with higher FA and SLS concentrations were not carried out because at these concentrations the plating bath became viscous and turbid.

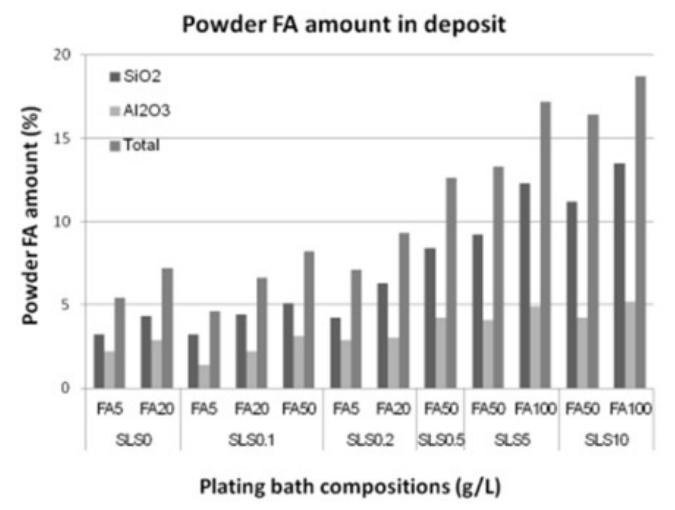

Figure 3. Relationship between individual and total amount of $\mathrm{SiO}_{2}, \mathrm{Al}_{2} \mathrm{O}_{3}$ (mass fraction, \%) in deposit with different compositions of plating bath (FA: 5-100 g/L; SLS: 0.1-10 g/L) 
Measurements of the surface charge of FA particles in the solution with different $\mathrm{pH}$ values were performed with Zeta Phoremeter CAD - Z3110 (French). The results indicated a low positive charge (zeta potential of $\sim 10 \mathrm{mV}$ ) at the FA surface in the solution with $\mathrm{pH}<4.5$ corresponding to $\mathrm{pH}$ of $\mathrm{Ni}$ plating solution. It agreed with data from reference [8].

Owing to the positive charge, according to the Guglielmi' model [28], the FA particles were adsorbed on the cathode, thus embedded in growing metal deposit. However, due to the low positive charge as well as adsorption competition with the Ni-cations, the amount of FA deposited on the cathode was not high.

As shown by Lee [29], the magnitude of the zeta potential of the particles was a measure of particles interaction. Since the zeta potential of the FA was less than $10 \mathrm{mV}$ - close to zero, the FA suspension was unstable and particle aggregation occurred resulting low amount of reinforcing particles in deposit $[12,13]$. However, the surfactant is able to improve the dispersion of inert particles facilitating the particles moved and bound to cathode; hence their amount in deposit was increased.

In the presence of a surfactant, the reinforcing particles are also affected by interacting with the surfactant [30]. It was plausible that a suitable surfactant could improve the stability of particle suspension and the charge of suspended particles and thus enhancing the electrostatic adsorption of the suspended particles on a cathode.

The adsorption of the SLS anions on the surface of positively charged FA particles formed a negative charge cloud on which Ni-cations could be adsorbed. This adsorption increased positive charge of FA particles accelerating both the electrophoretic movement of the FA particles towards the cathode and electrostatic attraction between the FA and the cathode. This dual action facilitated the codeposition of FA onto the cathodic surface. Since the presence of $\mathrm{Ni}$ cations on the surface of FA particles contributed to a high amount of FA codeposited on the cathode, the reduction of metal ions was considered as the key step in the process of co- deposition [30,31].

Experimental results showed that in the presence of surfactant SLS, at the concentration of FA of $50 \mathrm{~g} / \mathrm{L}$, the amount of FA deposited in the coating increased 2.3 times (from $8 \%$ to $18.8 \%$ (mass fraction); this amount increased by increasing simultaneously both FA and SLS concentration.

\section{Micro-hardness of coating}

Micro-hardness of the Ni/FA composite plating was summarized in Fig. 4. The values in the figure were an average of 10 different measured points for one sample. Clearly that micro-hardness of the Ni/FA composite coating was higher than that of pure Ni. As the FA concentration in the solution increased, the hardness of composite coating increased due to a higher amount of FA particles co-deposited in the coating. Furthermore, the amount of FA powder in coating increased with increasing SLS concentration resulting in an increase of the micro-hardness (Fig. 4). For example, comparison of micro-hardness of the coatings obtained at a given FA powder concentration $(50 \mathrm{~g} / \mathrm{L})$ but different SLS concentrations ( 0 and $10 \mathrm{~g} / \mathrm{L})$ indicates a good increase in micro-hardness. Indeed, it has been found that the micro-hardness was HV 270 for $0 \mathrm{~g} / \mathrm{L}$ of SLS, and HV 460 at $10 \mathrm{~g} / \mathrm{L}$ for SLS or $70.4 \%$ increase (Fig.5). Also, at the two extremes in Fig. 5 if the micro-hardness of Ni coating (HV 198) compared with that of composite coating achieved at FA concentration of $100 \mathrm{~g} / \mathrm{L}$ and SLS of $10 \mathrm{~g} / \mathrm{L}$ (HV 490), the increase was 147\% (or 2.5 times higher.

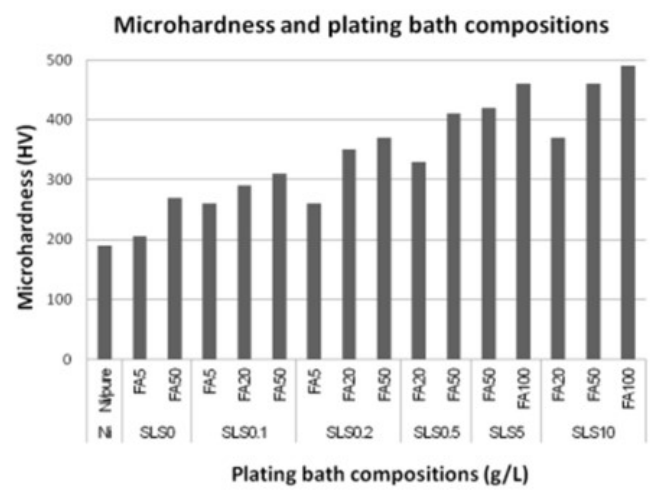

Figure 4. The Microhardness of Ni/FA composite coating (plating bath compositions: FA: 5-100 g/L; SLS: 0.1-10 g/L). 
A close examination of the microstructure of composite coating (Fig. 2b, 2c) revealed that some granular structures formed in the presence of SLS but the Ni maintained at a similar size. Although SLS affects the microstructure, however the enhancement of the micro-hardness was mainly dependent on the FA content in the coating.

\section{E. Electrochemical property of coating}

Fig. 5 shows typical anodic polarization curves of the $\mathrm{Ni}$ and $\mathrm{Ni} / \mathrm{FA}$ composite coating in the absence and presence of SLS in $3.5 \% \mathrm{NaCl}$ solution. From these curves, the electrochemical parameters of the $\mathrm{Ni}$ and the composite coatings were calculated and shown in the Table 1.

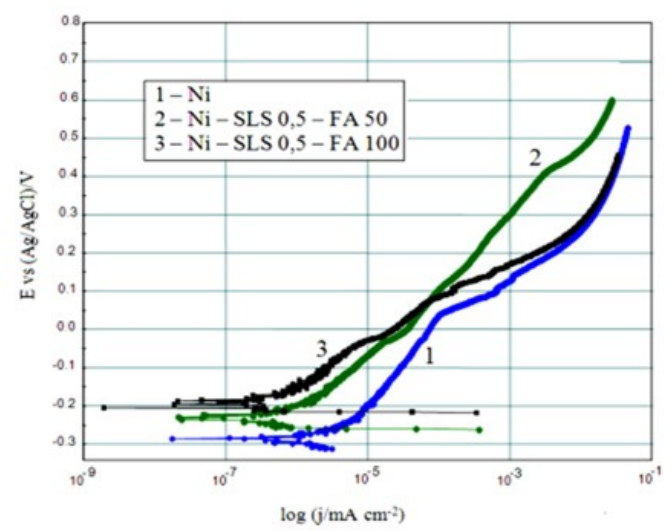

Figure 5. Anodic polarization curves of composite plating in $3.5 \% \mathrm{NaCl}$ (scan rate: $0.1 \mathrm{mV} / \mathrm{s}$ )

Table-1 Electrochemical Parameters of $\mathrm{Ni}$ and Ni/FA Composite Coatings

\begin{tabular}{cccccc}
\hline Sample & $E_{\text {corr }} /(\mathbf{m V})$ & $J_{\text {corr }} /\left(\mu \mathrm{A} / \mathrm{cm}^{2}\right)$ & $E_{\mathrm{pit}} /(\mathbf{m V})$ & $J_{\text {pit }} /\left(\mathbf{m A} / \mathrm{cm}^{2}\right)$ & $R_{\mathrm{p}} /\left(\mathbf{k} \Omega \mathbf{c m}^{2}\right)$ \\
\hline Ni & -280 & 1.048 & 105 & 0.775 & 18.85 \\
Ni/FA50 & -228 & 0.576 & 92 & 0.361 & 38.64 \\
Ni/FA50/SLS0.1 & -226 & 0.520 & 102 & 0.287 & 44.69 \\
Ni/FA50/SLS0.2 & -204 & 0.421 & 107 & 0.277 & 61.86 \\
Ni/FA50/SLS0.5 & -202 & 0.381 & 112 & 0.234 & 59.64 \\
Ni/FA50/SLS5.0 & -194 & 0.272 & 71 & 0.176 & 81.56 \\
Ni/FA50/SLS10.0 & -160 & 0.181 & 79 & 0.145 & 112.86 \\
Ni/FA100/SLS5.0 & -132 & 0.138 & 89 & 0.025 & 91.39 \\
\hline
\end{tabular}

Note: Each parameter is average values measured at least on the three samples

$E_{\text {corr }}$ : Corrosion potential, $J_{\text {corr: }}$ : Corrosion current density, $E_{\text {pit }}$ : Pitting potential, $J_{\text {pit: }}$ : pitting current density

From data listed in the Table 1, clearly that composite plating, particularly in the presence of SLS surfactant, was nobler in comparison with Ni-coating. In the $\mathrm{NaCl}$ solution, corrosion current density $J_{\text {corr }}\left(\mu \mathrm{A} / \mathrm{cm}^{2}\right)$ of Ni was 1.048; of Ni-FA50: 0.576; of Ni-FA50+SLS10: 0.181; polarization resistance $R_{\mathrm{p}}\left(\mathrm{k} \Omega \mathrm{cm}^{2}\right)$ was 18.85 for Ni; 38.64 for Ni-FA50 and 112.86 for Ni-FA50+SLS10, respectively. The corrosion resistance of Ni-FA composite is 2 times higher than that of $\mathrm{Ni}$, whilst Ni-FA+SLS nearly 6 time higher. It is thus proposed that the presence of reinforcing particles embedded in the Ni matrix resulted the finer microstructures and the narrower granular boundaries, even crevices, gaps, cracks and micro pores were filled by additives. These particulates act as an inert physical barrier against initiation and development of corrosion, hence improving the corrosion resistance [19].

By increasing FA concentration at a constant concentration of SLS, the corrosion resistance of composite increased, i.e. the corrosion current $\left(J_{\text {corr }}\right)$ decreased and the polarization resistance $\left(R_{\mathrm{p}}\right)$ increased. For example, at a SLS concentration of $5 \mathrm{~g} / \mathrm{L}$, corrosion current density is $0.272 \mu \mathrm{A} / \mathrm{cm}^{2}$, polarization resistance is $81.56 \mathrm{k} \Omega \mathrm{cm}^{2}$ at FA powder of $50 \mathrm{~g} / \mathrm{L}$, and $0.138 \mu \mathrm{A} / \mathrm{cm}^{2}$ and $91.39 \mathrm{k} \Omega \mathrm{cm}^{2}$ at FA powder of $100 \mathrm{~g} / \mathrm{L}$. 
In the case of a constant FA concentration, as the SLS concentration increased, the corrosion resistance of composite increased. For example, at $50 \mathrm{~g} / \mathrm{L}$ of FA, 0.1 and $\mathrm{g} / \mathrm{L}$ of SLS, the corrosion current density $\left(J_{\text {corr }}\right)$ decreased from 0.520 to $0.181 \mu \mathrm{A} / \mathrm{cm}^{2}\left(\sim 3\right.$ times). In all cases, the pitting potentials $\left(E_{\mathrm{pit}} / \mathrm{mV}\right)$ and the pitting current densities $\left(J_{\mathrm{pit}} / \mathrm{mA} / \mathrm{cm}^{2}\right)$ decreased. This again indicated enhancement of corrosion resistance of the composite coating.

\section{IV.CONCLUSION}

- As an anion surfactant, SLS did not affect on the cathodic kinetics of Ni cation. SLS exhibited a good stimulating effect to facilitate the co-deposition of FA in the Ni plating. The amount of FA in the deposit increased with the SLS concentrations. For example, at the FA concentration of $50 \mathrm{~g} / \mathrm{L}$, when SLS concentration of $0.1,5$ and $10 \mathrm{~g} / \mathrm{L}$, the FA powder amount in deposit was 8.2, 13.3 and $16.3 \%$ (mass fraction), respectively.

- The microhardness and corrosion resistance of the Ni/FA composite coatings were improved by an increasing amount of inert particles in the deposit that in turn was dependent on the FA and SLS concentrations in solution. Under selected plating conditions $\left(2 \mathrm{~A} / \mathrm{dm}^{2}, 250 \mathrm{r} / \mathrm{min}, 50{ }^{\circ} \mathrm{C}\right)$, at $50 \mathrm{~g} / \mathrm{L}$ of FA, $10 \mathrm{~g} / \mathrm{L}$ of SLS, microhardness of the coating increased 2.4 times, corrosion resistance about 6 times in comparison with pure Ni coating.

- As a stimulator, SLS facilitated more FA deposited into Ni matrix, thus higher microhardness and better corrosion resistance of the coatings were achieved.

\section{ACKNOWLEDGEMENTS}

The authors would like to thank to National Foundation for Science and Technology Development of VietnamNAFOSTED for the financial support provided by Contact Coded 104.03.117.09.

Authors would like to thank also Dr. V.-T. Truong of Defence Science and Technology Organisation of Australia for helpful discussion during preparation of the manuscript.

\section{REFERENCES}

[1] C.T.J. Low, R.G.A. Wills, F.C. Walsh, Electrodeposition of composite coatings containing nanoparticles in a metal deposit, Surf. and Coat. Technol., vol. 201, pp. 371-377, 2006.

[2] W.W. Chen, W. Gao, Sol-enhanced electroplating of nanostructured Ni-TiO2 composite coatings-The effects of sol concentration on the mechanical and corrosion properties, Electrochim. Acta., vol. 55, pp. 6865-6872, 2010, .

[3] R.K. Saha, T.I. Khan, Effect of applied current on the electrodeposited $\mathrm{Ni}-\mathrm{Al}_{2} \mathrm{O}_{3}$ composite coatings, Surf. and Coat. Technol.,vol. 205, pp. 890-895, 2010.

[4] B. Szczygieł, M. Kołodziej, Composite Ni/Al2O3 coatings and their corrosion resistance, Electrochim. Acta., vol. 50, pp. 4188-4197, 2005.

[5] Th. Lampke, Correlation between structure and corrosion behaviour of nickel dispersion coatings containing ceramic particles of different sizes, Surf. and Coat. Technol., vol. 201, pp. 3510-3517, 2006.

[6] N.K. Shrestha, I. Miwa, T. Saji, Composite plating of Ni/SiC using a cationic surfactant with an azobenzene group, J. Electrochem. Soc., vol. 148, C106, 2001.

[7] L.P. Wang, Y. Gao, H.W. Liu, T. Xu, Effects of bivalent Co ion on the co-deposition of nickel and nano-diamond particles, Surf. and Coat. Technol., vol.191, pp. 1-7, 2005.

[8] S.C. Wang, W. Cheng, J. Wei J, Kinetics of electroplating process of nano-sized ceramic particle/Ni composite, Mater. Chem. and Phys., vol. 78, pp. 574-683, 2003.

[9] J. Zahavi and A. Bodnevas, The influence of additives on composite pating, Bull. Electrochem., vol 8, pp. 363-370, 1992.

[10] E. Rudnik, L. Burzyńska, J. Jędruch, L. Błażb, Codeposition of SiC particles with electrolytic cobalt in the presence of Cs+ ions, Appl. Surf. Sci., vol. 255, pp. 67164-7170, 2009.

[11] T.J. Tuaweri, G.D. Wilcox, Behaviour of $\mathrm{Zn}-\mathrm{SiO}_{2}$ electrodeposition in the presence of $N, N$-dimethyldodecylamine, Surf. and coat. Technol., vol. 200, pp. 5921-5928, 2006.

[12] Z.A. Hamid and S.M. El-Sheikh, Enhancement the Properties of Ni Composite Electroplated Using Nano-Chromium Oxide Powder, Metallurg. Eng., vol.2, pp. 71-77, 2013.

[13] L. Wang, Z. Zeng, J. Zhang, L. Chen, Effect of surfactant on the electrodeposition and wear resistance of $\mathrm{Ni}^{-} \mathrm{Al}_{2} \mathrm{O}_{3}$ composite coatings, Mater. Sci. and Eng. vol. A 434, pp. 319-329, 2006.

[14] K.H. Hou, M.D. Ger, L.M. Wang, S.T. Ke, The wear behaviour of electro-codeposited Ni-SiC composites, Wear, vol. 253, pp. 994-999, 2002.

[15] A. Hoverstad, L.J.J. Janssen, Electrochemical codeposition of inert particles in a metallic matrix, J of App. Electrochem., vol. 25, pp. 519572, 1995.

[16] E. Rudnik, Influence of surface properties of ceramic particles on their incorporation into cobalt electroless deposits, Appl. Surf. Sci., vol. 255, pp. 2613-2620, 2008.

[17] G. Sharma, R.K. Yadava, and V.K. Sharma, Characteristics of electrocodeposited Ni-Co-SiC composite coating, Bull. Mater. Sci., vol. 29, pp. 491-497, 2006 (C) Indian Academy of Sciences. 
[18] K. Karuppusamy, R. Anantharam, C.J. Kennady, R.M. Krishnan and S.R. Natarajan, Pit-Free Nickel Electroplating, Met. Finish., May, pp. 15-21, 1992.

[19] H. Chitharanjan, Effect of surfactant on high capacitance of galvanostatically deposited MnO2, J. of Electroanalytical Chem. , vol. 676, pp. $35-44,2012$.

[20] Abbas Fahami, Bahman Nasiri-Tabrizi, Mohsen Rostami, and Reza Ebrahimi-Kahrizsangi, Electrochem., 2013, Article ID 486050 (http://dx.doi.org/10.1155/2013/486050) Hindawi Publishing Corporation.

[21] B.C. Tripathy, S.C. Das, G.T. Hefter, P. Singh, Zinc electrowinning from acidic sulfate solutions, Part I: Effects of sodium lauryl sulfate, J. of Appl. Electrochem., vol. 27, pp. 673-678, 1997.

[22] H.C. Anilkumar, H.S. Hebbar and K.S. Ravishankar, Mechanical properties of fly ash reinforced aluminium alloy. Indian J. Mechan. and Mater. Eng., (IJMME), vol.6, pp. 41-45, 2011.

[23] S.K. Acharya, P. Mishra, S.C. Mishra, Effect of environment on the mechanical properties of fly ash-jute-polymer composite, Ind J Eng Mater Sci., vol. 15, pp. 483-488, 2008.

[24] S.H. Bidkar, A.G. Patil, U.R. Kapadi \& D.G. Hundiwale, Evaluation of fly ash filled chloroprene elastomer composites, Indian Journal of Engineering \& Materials Sciences, vol. 12, pp. 351-355, 2005.

[25] C.N. Panagopoulos, E.P. Georgiou, A.G. Gavras, Composite zinc-fly ash coating on mild steel, Surf. and Coat. Technol., vol. 204, pp. 3741, 2009.

[26] N.N. Phong, N.V. Hue, N.T. Tuyet, P.H. Hanh, An application of Electrochemical Method for Studying Nano-Composite Plating, Met. and Mater. Inter., vol. 12, pp. 493-948, 2006.

[27] N.V. Hue, N.T.A.Tuyet, P.H. Hanh, N.N. Phong, Nickel Composite Plating with FA as Inert Particle, Trans. NonFerrous. Met. Soc. China, vol. 23, pp. 2348-2353, 2013.

[28] N. Guglielmi, Kinetics of the deposition of inert particles from electrolytic baths, J.Electrochem. Soc., vol. 119, pp. 1009-1015, 1972.

[29] 29. H.K. Lee, H.Y. Lee and J.M. Jeon, Electrolytic Deposition Behaviors of Ni-SiC Composite Coatings Containing Submicron-Sized SiC Particles, Met. and Mater. Inter., vol. 14, pp. 599-605, 2008.

[30] N.K. Shrestha, Compoaite Plating Using an Electro-active Surfactant $~$ A New Approach to Incorporate High Amount of Ceramic Particles into a Metallic Matrix, Surf. Finish. Soc. Jap., vol. 57, pp. 489-495, 2006.

[31] P. Nowak, R.P. Socha, M. Kaisheva, J. Fransaer, J.P. Celis and Z. Stoinov, Electrochemical investigation of the codeposition of SiC and $\mathrm{SiO} 2$ particles with nickel, Appl. Electrochem., vol. 30, pp. 429-437, 2000. 